\title{
Free-base Porphyrin Polymer for Bifunctional Electrochemical Water Splitting
}

\author{
Yulu Ge, Zhenhua Lyu, Mariana Marcos-Hernández, Dino Villagrán* \\ Department of Chemistry and Biochemistry, University of Texas at El Paso, El Paso, 79968, TX, United States \\ KEYWORDS: Water splitting; metal-free; bifunctional electrocatalysts
}

\begin{abstract}
Water splitting is considered a promising approach for renewable and sustainable energy conversion. The development of water splitting electrocatalysts that have low-cost, long-lifetime and high-performance is an important area of research for the sustainable generation of hydrogen and oxygen gas. Here, we report a metal-free porphyrin-based two-dimensional crystalline covalent organic polymer obtained from the condensation of terephthaloyl chloride and 5,10,15,20-tetrakis(4-aminophenyl) porphyrin which is stabilized by an extensive hydrogen bonding network. This material exhibits bifunctional electrocatalytic performance towards water splitting with onset overpotentials, $\eta$, of $36 \mathrm{mV}$ and $110 \mathrm{mV}$ for HER (in $0.5 \mathrm{M} \mathrm{H}_{2} \mathrm{SO}_{4}$ ) and OER (in $1.0 \mathrm{M} \mathrm{KOH}$ ), respectively. The as-synthesized material is also able to perform water splitting in neutral phosphate buffer saline solution, with 294 $\mathrm{mV}$ for HER and $520 \mathrm{mV}$ for OER, respectively. Characterized by electrochemical impedance spectroscopy (EIS) and chronoamperometry, the as-synthesized material also shows enhanced conductivity and stability compared to its molecular counterpart. Inserting a non-redox active zinc metal center in the porphyrin unit leads to a decrease of electrochemical activity towards both HER and OER, suggesting the four-nitrogen porphyrin core is the active site. The high performance of this metal-free material towards water splitting provides a sustainable alternative to the use of scarce and expensive metal electrocatalysts in energy conversion for industrial applications.
\end{abstract}

Global energy consumption increased drastically within the past 20 years and it is expected to continue to grow over the next several decades. ${ }^{1}$ The rapid depletion of non-renewable resources and their related combustion issues require the development of alternative energy sources and technologies with zero carbon footprint. ${ }^{2}$ Hydrogen is an ideal energy carrier due to its high energy density compared with conventional fossil fuels and because water is its only combustion byproduct. ${ }^{3,4}$ Currently, the production of hydrogen gas in industry is dependent on methane steam reforming which renders its production unsustainable and carbon positive..$^{5}$ Theoretically, water can be an abundant source of hydrogen if hydrogen and oxygen gases can be produced through electrolysis. Water splitting requires a four-electron redox process in addition to concomitant proton transfer, and high thermodynamic demands (1.23 eV at $\mathrm{pH} \mathrm{7.0).}{ }^{6}$ Current research efforts are focused on using renewable energy sources to induce water splitting directly ${ }^{7,8}$ or indirectly ${ }^{9,10}$ with minimal environmental effects. While electrochemical water splitting is effective and promising, ${ }^{11}$ commercial electrolyzers require robust and efficient catalysts to accomplish the hydrogen and the oxygen evolution reactions, HER and OER, respectively. ${ }^{6,12}$ Current electrocatalysts that meet these demands are based on scarce and expensive transition metals (i.e., Pt elements for HER and $\mathrm{RuO}_{2} / \mathrm{IrO}_{2}$ for OER). ${ }^{13-15}$ Thus, the use of single earth-abundant materials as bifunctional catalysts for both HER and OER is desired for sustainable and economic feasibility.

Porphyrins are organic macrocycles that have conjugated aromatic rings and characteristic intense colors. ${ }^{16}$ Porphyrinbased catalysts for water splitting have been exclusively focused on metalated complexes. ${ }^{17-26}$ The generation of highvalent metal-oxo intermediates is the key step to form molecular oxygen, where the porphyrin scaffold serves only as a molecular frame to facilitate the multi-electron transfer process, and a metal center is responsible for the catalytic activity. ${ }^{27,28,23}$ Similar mechanisms are invoked in HER which have metalhydride intermediates as proton transfer carriers. ${ }^{18-20}$

However, it has been shown that the catalytic activity of porphyrin complexes towards hydrogen generation does not necessarily require a metal center. ${ }^{29,30}$ The $\mathrm{N}-\mathrm{H}$ groups and $\mathrm{N}$ lone pairs in the core of free-base porphyrins can also act as active sites for hydrogen generation under acidic conditions. ${ }^{31}$ Electronic tuning at the meso-position by electron donating or withdrawing groups can yield porphyrin complexes with varied basicity that lead to distinct redox reactivity. ${ }^{32,33}$ Our previous work shows that a metal-free porphyrin with perfluorinated meso-substituted groups is able to electrocatalyze hydrogen generation in acid with a potential of $-1.31 \mathrm{~V}\left(\mathrm{vs} . \mathrm{Fc} / \mathrm{Fc}^{+}\right)$and $90 \%$ Faradaic efficiency. ${ }^{30}$ However, molecular level electrocatalysts suffer from stability issues, low current densities, high cost and non-recyclability for industrial utilization. $^{34}$ Therefore, to develop low-cost heterogeneous electrocatalysts that possess high reactivity and stability towards water splitting could be a promising strategy for hydrogen and oxygen production.

Poly( $p$-phenylene terephthalamide) (PPTA) fibers are a type of ultra-strong synthetic polymer with high tensile strength-to-weight ratio. ${ }^{35}$ The amide linkages form hydrogen 


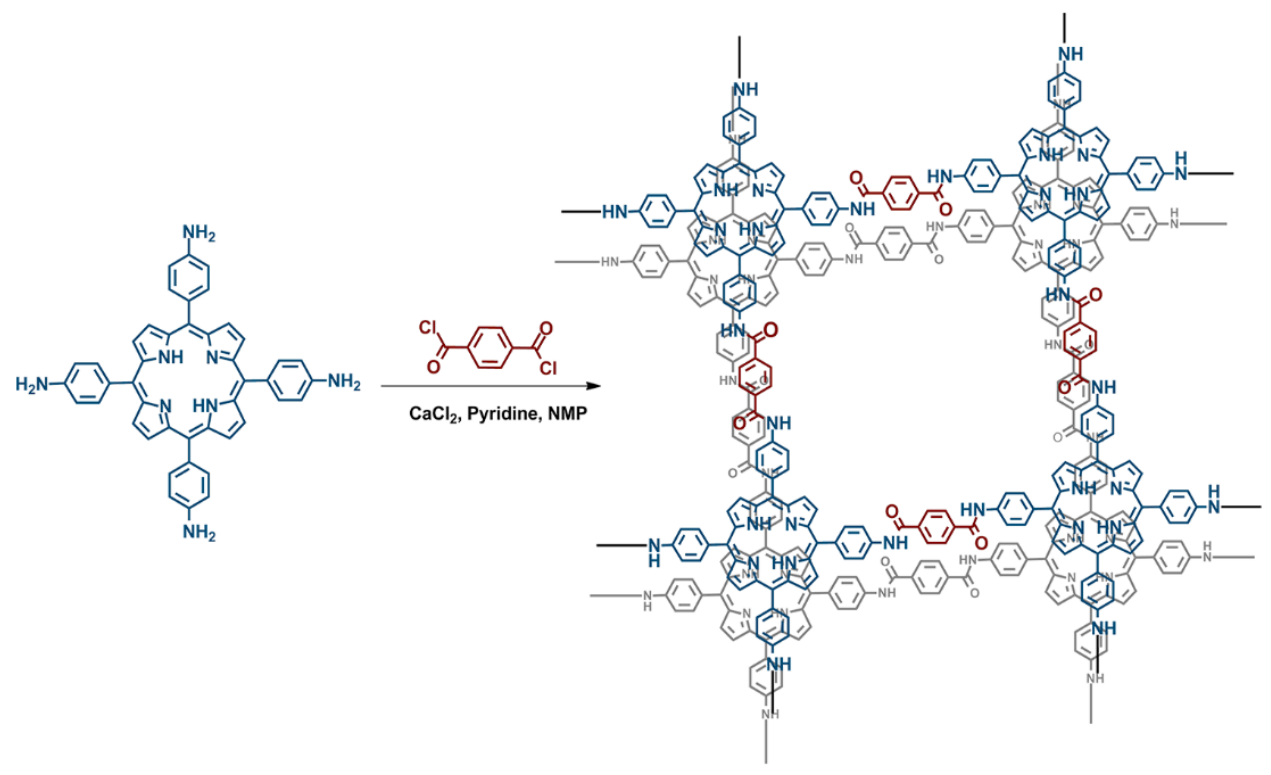

bonds between the polymer chains which act like "hydrogen bond locks", ${ }^{36}$ making it a material for bullet-proof body armors. ${ }^{37}$ Incorporating units of free-base porphyrins into PPTA networks can result in two-dimensional (2D) porphyrin-based polymers with ordered columnar $\pi$-arrays. Porphyrin moieties can enhance aromatic stacking interactions and add charge transport properties used in electrocatalytic applications. However, the use of metal-free porphyrin-based polymer as bifunctional electrocatalysts directly for both HER and OER is still underexplored.

In this work, we present the synthesis of a metal-free porphyrin based crystalline 2D organic polymer, Porphvlar, obtained from the condensation of terephthaloyl chloride and 5,10,15,20-tetrakis(4-aminophenyl porphyrin, namely $\mathrm{H}_{2}$ TAPP), which is an effective bifunctional electrocatalyst for the OER in basic conditions and the HER in neutral solutions. The electrochemical response of this material is explored under oxidation and reduction conditions in order to study its catalytic activity, charge transfer and stability.

Scanning electron microscopy (SEM) images were obtained to evaluate the morphology of the synthesized Porphvlar polymer in different magnifications. Figure 1A shows that the Porphvlar powder exhibits a flake-like morphology. The flakes are stacked in layers of a couple nanomenters in thickness. This is in contrast to the rod-like topology of PPTA threads. ${ }^{38}$ Energy-dispersive X-ray spectroscopy (EDX) (Figure S1) shows that only $\mathrm{C}, \mathrm{N}$ and $\mathrm{O}$ elements exist throughout the Porphvlar structure without the presence of any metal atoms that could have been incorporated through the synthetic processes.

The powder X-ray diffraction ( $p$-XRD) pattern in Figure 1B shows that the sample is microcrystalline. The $p$-XRD pattern of Porphvlar closely resembles the crystalline pattern of commercial PPTA. The diffraction peaks observed at $2 \theta=$ $24.1^{\circ}, 27.5^{\circ}, 28.4^{\circ}$ and $42.4^{\circ}$ correspond to the (1 110$),\left(\begin{array}{lll}2 & 0 & 0\end{array}\right)$, $\left(\begin{array}{lll}0 & 0 & 4\end{array}\right)$ and ( $\left.\begin{array}{lll}2 & 1 & 1\end{array}\right)$ planes, respectively, which are also present in PPTA fibers. ${ }^{39}$ The broad peak centered at around $2 \theta=20^{\circ}$ is attributed to $\pi$ - $\pi$ stacking between the 2D layers, where the porphyrin units form an AA type eclipsed stacking. ${ }^{47}$
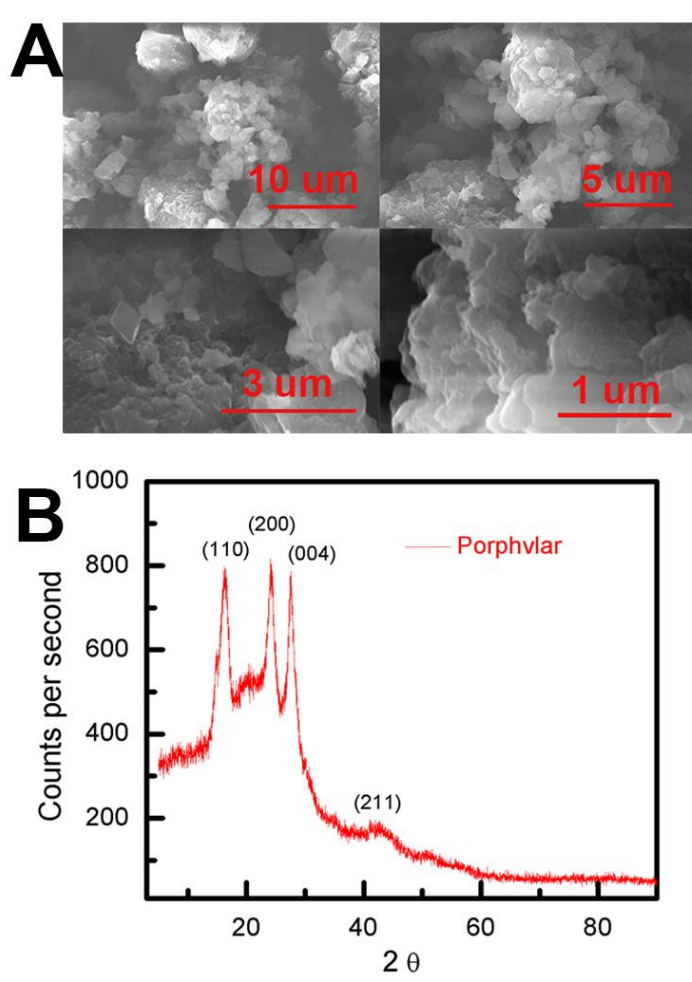

Figure 1. Morphology characterization of as-synthesized Porphvlar. (A) SEM microscopy in various scales. (B) p-XRD diffraction pattern.

The FT-IR and UV-vis spectra of Porphvlar were compared to those obtained from the molecular porphyrin unit, $\mathrm{H}_{2}$ TAPP. Figure 3A, shows the FT-IR spectra for both the porphyrin unit (top) and Porphvlar (bottom) materials. Porphvlar exhibits a band at $1785 \mathrm{~cm}^{-1}$ assigned to the amide I (carbonyl stretch, yellow region), the amide II band ( $\mathrm{N}-\mathrm{H}$ bend) appears around 

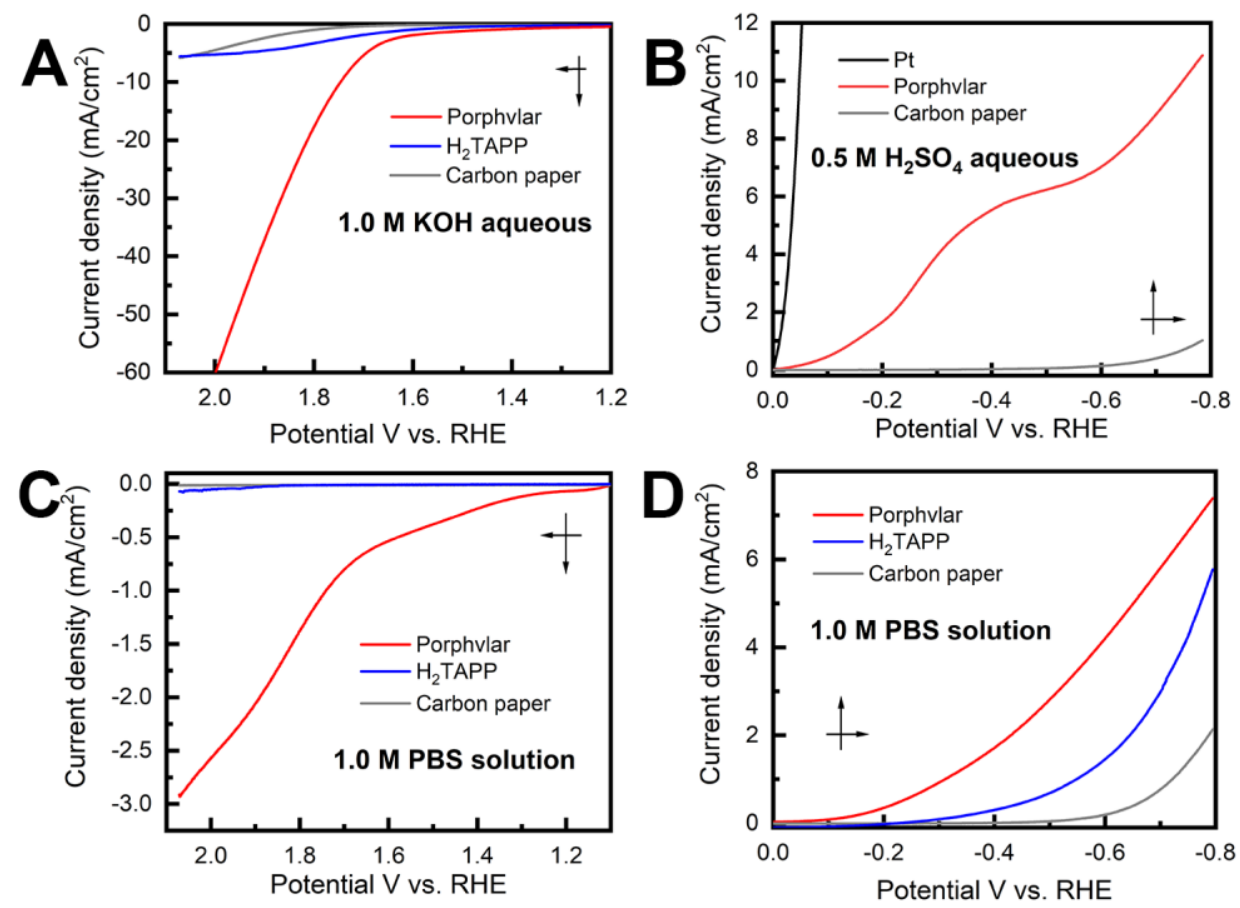

Figure 2. Polarization curves of molecular porphyrin ( $\left.\mathrm{H}_{2} \mathrm{TAPP}\right)$ (blue), Porphvlar (red) and blank carbon paper electrode under different conditions. (A) Oxidation in $1.0 \mathrm{M} \mathrm{KOH}$ aqueous solution; (B) Reduction in $0.5 \mathrm{M} \mathrm{H}_{2} \mathrm{SO}_{4}$ aqueous solution, (C) Oxidation in $1.0 \mathrm{M}$ PBS buffer solution; (D) Reduction in 1.0 M PBS buffer solution, scan rate: $5 \mathrm{mV} / \mathrm{s}$.

1500-1700 $\mathrm{cm}^{-1}$ (green region) and the amide III band is observed in the blue region. These bands indicate the formation of the amide group in the Porphvlar structure and are missing in the $\mathrm{H}_{2}$ TAPP spectrum. In addition, the $\gamma-(\mathrm{N}-\mathrm{H})$ pyrrole out-ofplane stretch is observed at $799 \mathrm{~cm}^{-1}$ in $\mathrm{H}_{2}$ TAPP and shifts to $\sim 1000 \mathrm{~cm}^{-1}$ in Porphvlar. Two primary amines $v-(\mathrm{N}-\mathrm{H})$ stretching bands at 3440 and $3356 \mathrm{~cm}^{-1}$ and one $\mathrm{sp}^{2} v-(\mathrm{C}-\mathrm{H})$ stretching peak $\left(3218 \mathrm{~cm}^{-1}\right)$ are visible in $\mathrm{H}_{2}$ TAPP, and those appear as a broad band around $3000 \mathrm{~cm}^{-1}$ in Porphvlar (pink region) due to hydrogen bonding between the polymer layers. Figure 3B shows the UV-vis spectra of $\mathrm{H}_{2}$ TAPP and Porphvlar. $\mathrm{H}_{2}$ TAPP has the indicative spectrum of a free-base porphyrin with a Soret band at $429 \mathrm{~nm}$ along with its corresponding Qbands between 521 to $663 \mathrm{~nm}$. Porphvlar shares a similar spectrum where the Soret and Q bands are blue-shifted by about $4 \mathrm{~nm}$. This indicates that the porphyrin unit is incorporated into the Porphvlar network.

The OER electrocatalytic activity evaluation of the resulting Porphvlar was performed in 1.0 M KOH aqueous solution and 1.0 M phosphate-buffer saline solution (PBS) with carbon paper as the conductive support electrode. The carbon black/carbon paper blank electrode has a negligible current increase. In $\mathrm{KOH}$ solution, Porphvlar exhibits a current increase at $1.63 \mathrm{~V}\left(\eta_{l}=\right.$ $400 \mathrm{mV}$ ) where the sharp increase is observed. The molecular porphyrin, $\mathrm{H}_{2} \mathrm{TAPP}$, has a similar onset potential where catalytic current is observed but with a lower current response (Figure 3A, blue line). These onset overpotentials are lower than those from reported metalated porphyrin composite materials $\left(\mathrm{rGO} /\left(\mathrm{Ni}^{2+} / \mathrm{THPP} / \mathrm{Co}^{2+} / \mathrm{THPP}\right)_{\mathrm{n}} \text { : } 1.49 \mathrm{~V} \text { vs } \mathrm{RHE}\right)^{41}$ and other metal based OER catalysts (FeNi LDH/GO: $1.439 \mathrm{~V}$ vs $\mathrm{RHE})^{42}$ and metal-free carbon/graphene based mutifunctional electrocatalysts (2D-N,S doped graphitic sheets: $1.49 \mathrm{~V}$ vs. RHE) ${ }^{43}$ in heterogeneous systems.
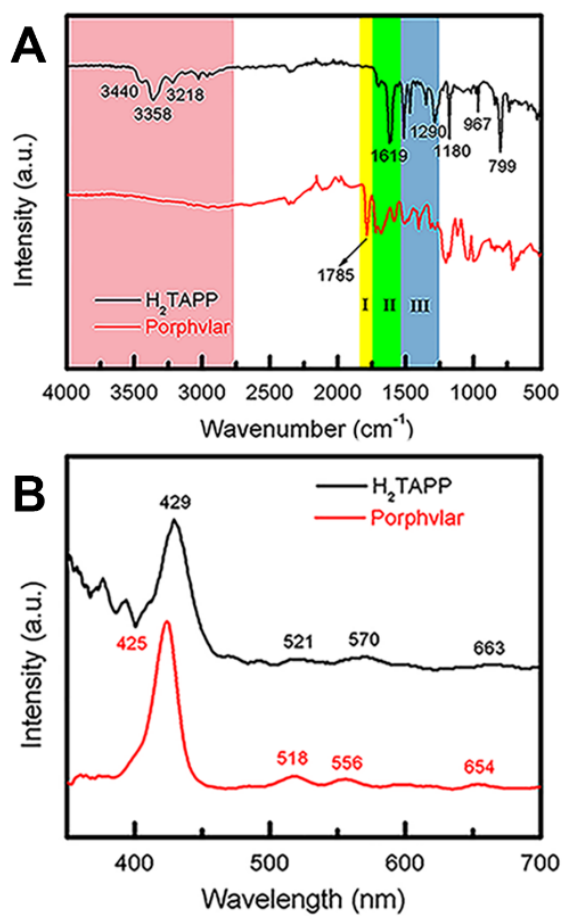

Figure 3. Spectroscopic characterization of Porphvlar. (A) FT-IR spectra of Porphvlar and molecular porphyrin $\left(\mathrm{H}_{2} \mathrm{TAPP}\right)$. (B) Comparison UV-vis spectra of Porphvlar and $\mathrm{H}_{2}$ TAPP. 

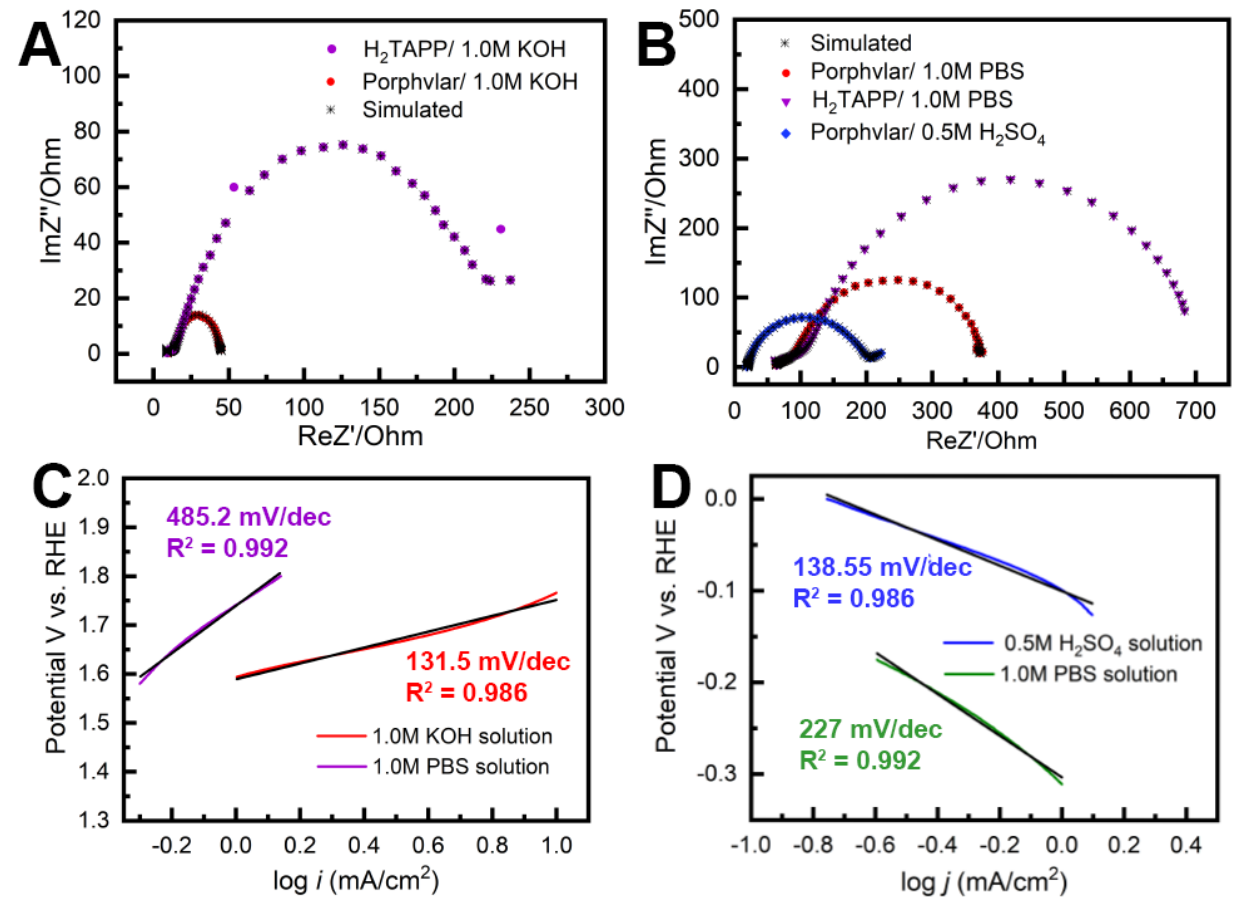

Figure 4. Electrochemical impedance spectroscopy of Porphvlar (red) and $\mathrm{H}_{2} \mathrm{TAPP}$ (purple) operated at $250 \mathrm{mV}$ overpotential: (A) in $1.0 \mathrm{M}$ $\mathrm{KOH}$ aqueous solution (B) in $1.0 \mathrm{M}$ PBS buffer solution and $0.5 \mathrm{M} \mathrm{H}_{2} \mathrm{SO}_{4}$ aqueous solution (blue), respectively; Tafel plots of Porphvlar constructed by polarization curves: (C) in $1.0 \mathrm{M} \mathrm{KOH}$ aqueous solution (red) and 1.0 M PBS buffer (purple); (D) $1.0 \mathrm{M}$ PBS buffer solution (green) and $0.5 \mathrm{M} \mathrm{H}_{2} \mathrm{SO}_{4}$ aqueous solution (blue)

The current response of Porphvlar reaches a current density of $10 \mathrm{~mA} / \mathrm{cm}^{2}$ at $1.75 \mathrm{~V}\left(\eta_{10}=520 \mathrm{mV}\right)$, while the molecular porphyrin plateaus at $5 \mathrm{~mA} / \mathrm{cm}^{2}$. The electrocatalytic OER performance for Porphvlar was also investigated in neutral PBS. As depicted in Figure 3C, the current density of Porphvlar increases slowly at $1.31 \mathrm{~V}$ vs. RHE until $1.63 \mathrm{~V}$ vs. RHE. Porphvlar requires an overpotential of $520 \mathrm{mV}$ to achieve a current density of $1 \mathrm{~mA} / \mathrm{cm}^{2}$, however, the molecular $\mathrm{H}_{2} \mathrm{TAPP}$ shows negligible current increase under the same conditions. The generated gas obtained from bulk electrolysis during $60 \mathrm{~h}$ was collected in a gas-tight H-type cell, and was confirmed to be $\mathrm{O}_{2}$ by gas chromatography with $92.7 \%$ Faradaic efficiency.

Figure 2B shows the HER electrocatalytic activity of Porphvlar in $0.5 \mathrm{M} \mathrm{H}_{2} \mathrm{SO}_{4}$ aqueous solution. The Pt electrode is shown as a benchmark for HER. Porphvlar has an onset potential of $36 \mathrm{mV}$ vs. RHE and reaches a current density of 1 $\mathrm{mA} / \mathrm{cm}^{2}$ at $177 \mathrm{mV} . \mathrm{H}_{2}$ TAPP does not perform HER in $0.5 \mathrm{M}$ $\mathrm{H}_{2} \mathrm{SO}_{4}$ aqueous solution. Under neutral reduction conditions, Porphvlar also shows electrocatalytic activity (Figure 3d) with an onset overpotential of $77 \mathrm{mV}$ vs. RHE $\left(\eta_{l}=294 \mathrm{mV}\right)$. The collected reduction product was confirmed to be hydrogen gas by gas chromatography with a Faradaic efficiency of $30.63 \%$ in acidic electrolyte and $99.55 \%$ in PBS buffer. The observed overpotential is comparable to most reported metal based HER catalysts in neutral media (Table S1).

Additionally, the porphyrin unit was metalated with zinc using standard synthetic procedures (see SI). Figure S15 shows Zn-Porphvlar exhibits considerably lower current response towards HER and OER with respect to the corresponding metalfree materials. This suggests that the catalytic center is located at the four-nitrogen core in the free-base porphyrin units. Thus, incorporating a redox inactive metal ion such as $\mathrm{Zn}$ can effectively shut down Porphvlar's activity towards catalyzing water splitting electrochemically. However, in 1.0 M PBS buffer, Zn-Porphvlar exhibits a similar HER overpotential and current density as the metal-free Porphvlar under the same conditions. This suggests that at neutral $\mathrm{Ph}$, a different active center participates in HER. At 1.0 M PBS, Zn-Porphvlar shows much lower current density for OER than the free-base Porphvlar counterpart.

The kinetic properties of Porphvlar and $\mathrm{H}_{2}$ TAPP under oxidation and reduction conditions within different electrolytes were characterized by electrochemical impedance spectroscopy (EIS) in order to study the interface charge transport process. The Nyquist plots of Porphvlar and $\mathrm{H}_{2}$ TAPP, obtained by measuring the parametric response of the imaginary part vs. real part of the impedance, are shown in Figure 4A, B and S10. The diameter of the semicircle relates to the electron transfer process from the electrode surface into the electrolyte solution since it arises from the parallel combination of Faradaic charge transfer resistance and non-Faradaic double-layer capacitance. Therefore, the smaller the semicircle the less the charge transfer resistance. ${ }^{47,48}$ It can be seen that the semicircle in the highfrequency range of the Nyquist plot of Porphvlar has a smaller diameter than that of the molecular porphyrin unit under both oxidation and reduction conditions. This suggests that the Porphvlar network favors charge transfer during water splitting. Furthermore, the increased electron transfer from the modified electrode to the electrolyte enhances the catalytic activity towards both HER and OER. 
In order to evaluate the kinetics during the electrolysis process, Tafel plots were constructed from polarization curves (Fig 4C and D). The linear portions of the Tafel plots were fit to the Tafel equation: $\eta=b \log \log j+a$, where $\eta$ is the overpotential, $j$ is the current density, and $\mathrm{b}$ is the Tafel slope. The calculated Tafel slope for Porphvlar $(131.5 \mathrm{mV} / \mathrm{dec})$ in a 1.0 $\mathrm{M} \mathrm{KOH}$ solution is comparable to that of the benchmark OER electrocatalyst $\mathrm{IrO}_{2}(83 \mathrm{mV} / \mathrm{dec}),{ }^{44}$ suggesting fast reaction kinetics and high OER activity. In $0.5 \mathrm{M} \mathrm{H}_{2} \mathrm{SO}_{4}$ solution, Porphvlar has an HER Tafel slope of $138.55 \mathrm{mV} / \mathrm{dec}$, also indicates efficient kinetics. The general HER mechanism in metal surfaces has been extensively studied, and three mechanisms have been proposed for the different Tafel slopes: Volmer (120 mV/dec), Heyrovsky (40 mV/dec ) and Tafel (30 $\mathrm{mV} / \mathrm{dec}$ ). ${ }^{45}$ The Porphvlar HER Tafel slopes (in neutral and acidic conditions) suggest a Volmer-Heyrovsky mechanism via water reduction $\left(\mathrm{H}_{2} \mathrm{O}+e^{-}=\mathrm{H}_{a d s}+\mathrm{OH}^{-}\right.$and $\mathrm{H}_{2} \mathrm{O}+e^{-}+$ $\left.\mathrm{H}_{\text {ads }}=\mathrm{H}_{2}+\mathrm{OH}^{-}\right){ }^{46}$ The Tafel slopes are larger for HER and OER when using PBS as an electrolyte, these slow kinetics might be due to the low ion concentration and $\mathrm{pH}$ in the reaction.

The long-term stability of Porphvlar in different electrolytes under both oxidation and reduction conditions, was studied with bulk electrolysis for 60 hours. Figure 5 shows that Porphvlar exhibits constant and stable anodic and cathodic currents during OER and HER electrocatalysis, respectively, within this timeframe. The durability of Porphvlar can be attributed to the stability of the conjugated porphyrin networks and the hydrogen bonding within its layers that result in a unique catalytic material for HER and OER.

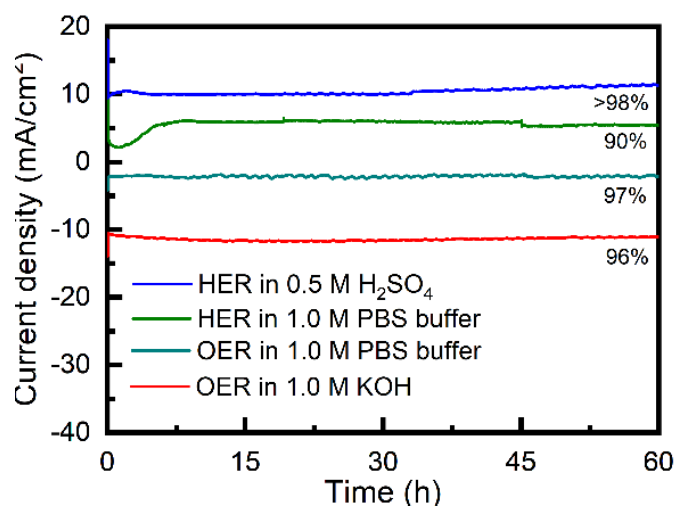

Figure 5. Time dependence of the current density for assynthesized Porphvlar at static potential. Current density at around $10 \mathrm{~mA}$ for HER in $1.0 \mathrm{M} \mathrm{KCl}$ solution (green) and $5 \mathrm{~mA}$ for OER in $1.0 \mathrm{M} \mathrm{KOH}$ (red).

In summary, an efficient and stable metal-free electrocatalyst for HER and OER has been developed. This bifunctional material was constructed through the condensation of (4-aminophenyl) porphyrin ( $\left.\mathrm{H}_{2} \mathrm{TAPP}\right)$ into PPTA networks. The HER and OER catalytic performances are higher than those of other metal-free materials and comparable or better than several traditional metallic electrocatalysts. The catalytic ability of Porphvlar which occurs at the molecular porphyrin nodes is further enhanced by the 2D network arrangement of the hydrogen-bonded PPTA networks. This material provides a novel approach into the design of metal-free electrocatalysts and takes advantage of the structural interactions within a $2 \mathrm{D}$ network to yield high electrochemical performance, conductivity and durability.

\section{ASSOCIATED CONTENT}

\section{Supporting Information}

The Supporting Information is available free of charge on the ACS Publications website.

Details of $\mathrm{H}_{2}$ TAPP and Porphvlar synthesis, ${ }^{1} \mathrm{H}$ NMR experiments, electrochemical measurements in acid and phosphate buffer solutions, including Figures S1-S5 and Table S1 and Table S2 (PDF)

\section{AUTHOR INFORMATION}

\section{Corresponding Author}

* Dino Villagrán - Department of Chemistry and Biochemistry, University of Texas at El Paso, El Paso, TX, 79968, United States;

\section{Author Contributions}

D. Villagran and Y. Ge conceived and designed the experiments. Z. Lyu and Y. Ge synthesized the materials, performed the FT-IR and UV-vis characterization and electrochemical experiments. M. Marcos-Hernandez performed the $p$-XRD, and SEM-EDX mapping measurements. All authors analyzed the data, discussed the results and reviewed the manuscript.

\section{Funding Sources}

This work was supported in part by ONR under award number ONR N00014-19-1-2467.

\section{ACKNOWLEDGMENT}

MMH acknowledges financial support from CONACYT (Mexico). We thank Prof. Geoffrey Saupe for access to a GC instrument.

\section{REFERENCES}

(1) Lewis, N. S.; Nocera, D. G. Powering the Planet: Chemical Challenges in Solar Energy Utilization. PNAS 2006, 103 (43), 15729-15735.

(2) Kabir, E.; Kumar, P.; Kumar, S.; Adelodun, A. A.; Kim, K.H. Solar Energy: Potential and Future Prospects. Renew. Sust. Energ. Rev. 2018, 82, 894-900.

(3) Winsche, W. E.; Hoffman, K. C.; Salzano, F. J. Hydrogen: Its Future Role in the Nation's Energy Economy. Science 1973, 180 (4093), 1325-1332.

(4) Gholipour, M. R.; Dinh, C.-T.; Béland, F.; Do, T.-O. Nanocomposite Heterojunctions as Sunlight-Driven Photocatalysts for Hydrogen Production from Water Splitting. Nanoscale 2015, 7 (18), 8187-8208.

(5) Rostrup-Nielsen, J. R. Fuels and Energy for the Future: The Role of Catalysis. Catal. Rev. 2004, 46 (3-4), 247-270.

(6) Wang, F.; Ahmed Shifa, T.; Zhan, X.; Huang, Y.; Liu, K.; Cheng, Z.; Jiang, C.; He, J. Recent Advances in TransitionMetal Dichalcogenide Based Nanomaterials for Water Splitting. Nanoscale 2015, 7 (47), 19764-19788.

(7) Wang, Y.; Wang, Q.; Zhan, X.; Wang, F.; Safdar, M.; He, J. Visible Light Driven Type II Heterostructures and Their Enhanced Photocatalysis Properties: A Review. Nanoscale 2013, 5 (18), 8326-8339.

(8) Park, M.-S.; Kang, M. The Preparation of the Anatase and Rutile Forms of $\mathrm{Ag}-\mathrm{TiO}_{2}$ and Hydrogen Production from 
Methanol/Water Decomposition. Mater. Lett. 2008, 62 (2), 183-187.

Greeley, J.; Jaramillo, T. F.; Bonde, J.; Chorkendorff, I.; Nørskov, J. K. Computational High-Throughput Screening of Electrocatalytic Materials for Hydrogen Evolution. Nat. Mater. 2006, 5 (11), 909-913.

(10) Chhowalla, M.; Shin, H. S.; Eda, G.; Li, L.-J.; Loh, K. P.; Zhang, H. The Chemistry of Two-Dimensional Layered Transition Metal Dichalcogenide Nanosheets. Nat. Chem. 2013, 5 (4), 263-275.

(11) Yan, Y.; Yu Xia, B.; Zhao, B.; Wang, X. A Review on NobleMetal-Free Bifunctional Heterogeneous Catalysts for Overall Electrochemical Water Splitting. J. Mater. Chem. A 2016, 4 (45), 17587-17603.

(12) Cobo, S.; Heidkamp, J.; Jacques, P.-A.; Fize, J.; Fourmond, V.; Guetaz, L.; Jousselme, B.; Ivanova, V.; Dau, H.; Palacin, S.; et al. A Janus Cobalt-Based Catalytic Material for ElectroSplitting of Water. Nat. Mater. 2012, 11 (9), 802-807.

(13) Lee, Y.; Suntivich, J.; May, K. J.; Perry, E. E.; Shao-Horn, Y. Synthesis and Activities of Rutile $\mathrm{IrO}_{2}$ and $\mathrm{RuO}_{2}$ Nanoparticles for Oxygen Evolution in Acid and Alkaline Solutions. J. Phys. 2012, 3 (3), 399-404.

(14) Reier, T.; Oezaslan, M.; Strasser, P. Electrocatalytic Oxygen Evolution Reaction (OER) on $\mathrm{Ru}$, Ir, and Pt Catalysts: A Comparative Study of Nanoparticles and Bulk Materials. ACS Catal. 2012, 2 (8), 1765-1772.

(15) Antolini, E. Iridium As Catalyst and Cocatalyst for Oxygen Evolution/Reduction in Acidic Polymer Electrolyte Membrane Electrolyzers and Fuel Cells. ACS Catal. 2014, 4 (5), 1426-1440.

(16) Anderson, H. L. Conjugated Porphyrin Ladders. Inorg. Chem. 1994, 33 (5), 972-981.

(17) Abe, T.; Taguchi, F.; Imaya, H.; Zhao, F.; Zhang, J.; Kaneko, M. Highly Active Electrocatalysis by Cobalt Tetraphenylporphyrin Incorporated in a Nafion Membrane for Proton Reduction. Polym. Advan. Technol. 1998, 9 (9), 559562.

(18) Bhugun, I.; Lexa, D.; Savéant, J.-M. Homogeneous Catalysis of Electrochemical Hydrogen Evolution by $\operatorname{Iron}(0)$ Porphyrins. J. Am. Chem. Soc. 1996, 118 (16), 3982-3983.

(19) Grass, V.; Lexa, D.; Savéant, J.-M. Electrochemical Generation of Rhodium Porphyrin Hydrides. Catalysis of Hydrogen Evolution. J. Am. Chem. Soc. 1997, 119 (32), 7526-7532.

(20) Lee, C. H.; Dogutan, D. K.; Nocera, D. G. Hydrogen Generation by Hangman Metalloporphyrins. J. Am. Chem. Soc. 2011, 133 (23), 8775-8777.

(21) Bediako, D. K.; Solis, B. H.; Dogutan, D. K.; Roubelakis, M. M.; Maher, A. G.; Lee, C. H.; Chambers, M. B.; HammesSchiffer, S.; Nocera, D. G. Role of Pendant Proton Relays and Proton-Coupled Electron Transfer on the Hydrogen Evolution Reaction by Nickel Hangman Porphyrins. PNAS 2014, 111 (42), 15001-15006.

(22) Zhang, Y.-Q.; Liao, R.-Z. Reaction Mechanism of Hydrogen Evolution Catalysed by $\mathrm{Co}$ and Fe Complexes Containing a Tetra-Dentate Phosphine Ligand - a DFT Study. Phys. Chem. Chem. Phys. 2017, 19 (48), 32589-32596.

(23) Zhang, W.; Lai, W.; Cao, R. Energy-Related Small Molecule Activation Reactions: Oxygen Reduction and Hydrogen and Oxygen Evolution Reactions Catalyzed by Porphyrin- and Corrole-Based Systems. Chem. Rev. 2017, 117 (4), 37173797.

(24) Wurster, B.; Grumelli, D.; Hötger, D.; Gutzler, R.; Kern, K. Driving the Oxygen Evolution Reaction by Nonlinear Cooperativity in Bimetallic Coordination Catalysts. J. Am. Chem. Soc. 2016, 138 (11), 3623-3626.

(25) Naruta, Y.; Sasayama, M.; Sasaki, T. Oxygen Evolution by Oxidation of Water with Manganese Porphyrin Dimers. Angew. Chem. Int. Ed. Engl. 1994, 33 (18), 1839-1841.

(26) Cui, S.; Qian, M.; Liu, X.; Sun, Z.; Du, P. A Copper Porphyrin-Based Conjugated Mesoporous Polymer-Derived

Bifunctional Electrocatalyst for Hydrogen and Oxygen Evolution. ChemSusChem 2016, 9 (17), 2365-2373.

Holm, R. H. Metal-Centered Oxygen Atom Transfer Reactions. Chem. Rev. 1987, 87 (6), 1401-1449.

Cheng, M.-J.; Head-Gordon, M.; Bell, A. T. How to Chemically Tailor Metal-Porphyrin-Like Active Sites on Carbon Nanotubes and Graphene for Minimal Overpotential in the Electrochemical Oxygen Evolution and Oxygen Reduction Reactions. J. Phys. Chem. C 2014, 118 (51), 29482-29491.

Patra, B. C.; Khilari, S.; Manna, R. N.; Mondal, S.; Pradhan, D.; Pradhan, A.; Bhaumik, A. A Metal-Free Covalent Organic Polymer for Electrocatalytic Hydrogen Evolution. ACS Catal. 2017, 7 (9), 6120-6127.

Wu, Y.; Rodríguez-López, N.; Villagrán, D. Hydrogen Gas Generation Using a Metal-Free Fluorinated Porphyrin. Chem. Sci. 2018, 9 (20), 4689-4695.

Swierk, J. R.; Méndez-Hernández, D. D.; McCool, N. S.; Liddell, P.; Terazono, Y.; Pahk, I.; Tomlin, J. J.; Oster, N. V.; Moore, T. A.; Moore, A. L.; et al. Metal-Free Organic Sensitizers for Use in Water-Splitting Dye-Sensitized Photoelectrochemical Cells. PNAS 2015, 112 (6), 1681-1686. Medforth, C. J.; Senge, M. O.; Smith, K. M.; Sparks, L. D.; Shelnutt, J. A. Nonplanar Distortion Modes for Highly Substituted Porphyrins. J. Am. Chem. Soc. 1992, 114 (25), 9859-9869.

Ito, A.; Konishi, K.; Aida, T. Free Bases of Chiral NSubstituted Porphyrins as Catalysts for Asymmetric Reaction. Tetrahedron Lett. 1996, 37 (15), 2585-2588.

Feng, D.-M.; Zhu, Y.-P.; Chen, P.; Ma, T.-Y. Recent Advances in Transition-Metal-Mediated Electrocatalytic $\mathrm{CO}_{2}$ Reduction: From Homogeneous to Heterogeneous Systems. Catalysts 2017, 7 (12), 373.

Penn, L.; Larsen, F. Physicochemical Properties of Kevlar 49 Fiber. J. Appl. Polym. 1979, 23 (1), 59-73.

Tanner, D.; Fitzgerald, J. A.; Phillips, B. R. The Kevlar Story-an Advanced Materials Case Study. Angew. Chem. Int. Ed. Engl. 1989, 28 (5), 649-654.

Li, L. S.; Allard, L. F.; Bigelow, W. C. On the Morphology of Aromatic Polyamide Fibers (Kevlar, Kevlar-49, and PRD49). J. Macromol. Sci. B 1983, 22 (2), 269-290.

Bala Murali Krishna, M.; Venkatramaiah, N.; Venkatesan, R.; Narayana Rao, D. Synthesis and Structural, Spectroscopic and Nonlinear Optical Measurements of Graphene Oxide and Its Composites with Metal and Metal Free Porphyrins. J. Mater. Chem. 2012, 22 (7), 3059.

Yeager, M. P.; Hoffman, C. M.; Xia, Z.; Trexler, M. M. Method for the Synthesis of Para-Aramid Nanofibers. J. Appl. Polym. 2016, 133 (42).

Bhunia, S.; Das, S. K.; Jana, R.; Peter, S. C.; Bhattacharya, S.; Addicoat, M.; Bhaumik, A.; Pradhan, A. Electrochemical Stimuli-Driven Facile Metal-Free Hydrogen Evolution from Pyrene-Porphyrin-Based Crystalline Covalent Organic Framework. ACS Appl. Mater. Interfaces 2017, 9 (28), 23843-23851.

Sun, J.; Yin, H.; Liu, P.; Wang, Y.; Yao, X.; Tang, Z.; Zhao, H. Molecular Engineering of Ni-/Co-Porphyrin Multilayers on Reduced Graphene Oxide Sheets as Bifunctional Catalysts for Oxygen Evolution and Oxygen Reduction Reactions. Chem. Sci. 2016, 7 (9), 5640-5646.

Xiang, Q.; Li, F.; Chen, W.; Ma, Y.; Wu, Y.; Gu, X.; Qin, Y.; Tao, P.; Song, C.; Shang, W.; et al. In Situ Vertical Growth of $\mathrm{Fe}-\mathrm{Ni}$ Layered Double-Hydroxide Arrays on Fe-Ni Alloy Foil: Interfacial Layer Enhanced Electrocatalyst with Small Overpotential for Oxygen Evolution Reaction. ACS Energy Lett. 2018, 3 (10), 2357-2365.

$\mathrm{Hu}, \mathrm{C}$; Dai, L. Multifunctional Carbon-Based Metal-Free Electrocatalysts for Simultaneous Oxygen Reduction, Oxygen Evolution, and Hydrogen Evolution. Adv. Mater. 2017, 29 (9), 1604942. 
(44) Zhu, Y.; Zhou, W.; Zhong, Y.; Bu, Y.; Chen, X.; Zhong, Q.; Liu, M.; Shao, Z. A Perovskite Nanorod as Bifunctional Electrocatalyst for Overall Water Splitting. Adv. Energy Mater. 2017, 7 (8), 1602122.

(45) Fang, Y.-H.; Liu, Z.-P. Tafel Kinetics of Electrocatalytic Reactions: From Experiment to First-Principles. ACS Catal. 2014, 4 (12), 4364-4376.

(46) Shinagawa, T.; Garcia-Esparza, A. T.; Takanabe, K. Insight on Tafel Slopes from a Microkinetic Analysis of Aqueous Electrocatalysis for Energy Conversion. Sci. Rep. 2015, 5 (1).
(47) Chang, B.-Y.; Park, S.-M. Electrochemical Impedance Spectroscopy. Annu. Rev. Anal. Chem. 2010, 3 (1), 207-229.

(48) Lasia, A. Electrochemical Impedance Spectroscopy and Its Applications. In Modern Aspects of Electrochemistry; Conway, B. E., Bockris, J. O., White, R. E., Eds.; Modern Aspects of Electrochemistry; Springer US: Boston, MA, 2002; pp 143-248. 


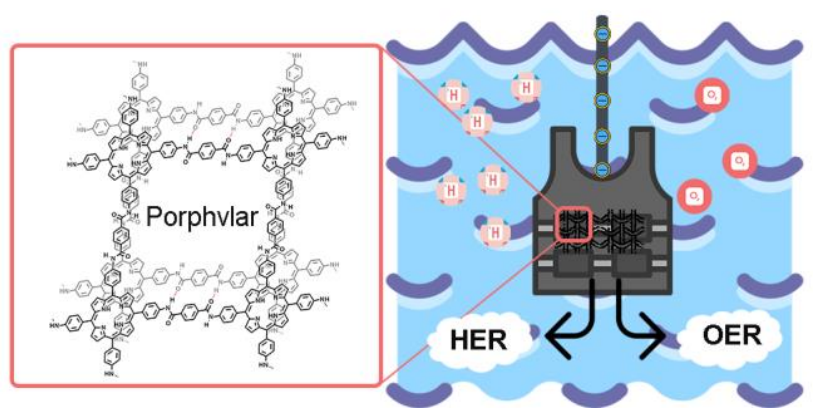

